\title{
A Pre-Design Sensitivity Analysis Tool for Consideration of Full- Electric Aircraft Propulsion Electrical Power System Architectures
}

\author{
C.E.Jones, P.J. Norman, S.J. Galloway, G.M. Burt \\ Institute for Energy and Environment \\ University of Strathclyde \\ Glasgow, UK \\ catherine.e.jones@strath.ac.uk
}

\author{
M. Armstrong, A. Bollman \\ Electrical Power and Control Systems \\ Rolls-Royce North America \\ Indianapolis, IN, USA
}

\begin{abstract}
Turbo-electric distributed power (TeDP) systems proposed for hybrid wing body (HWB) N3-X aircraft are complex, superconducting electrical networks, which must be developed to meet challenging weight, efficiency and propulsor power requirements. An integrated system sensitivity analysis tool is presented, which can be used to support rapid appraisal studies of architectures, protection systems and redundancy requirements for TeDP systems. The use of this tool can help direct future research on TeDP systems towards the key challenges relevant to meeting the stringent weight and efficiency targets set out for $\mathrm{N}+3$ aircraft concepts.
\end{abstract}

Keywords - Turbo-electric distributed propulsion (TeDP); sensitivity analysis; superconducting systems; aircraft.

\section{INTRODUCTION}

NASA has published ambitious performance, noise and emissions targets for $\mathrm{N}+3$ aircraft [1], which can meet future environmental demand for air travel [2]. A tight time frame of circa 10 years has been proposed to achieve a technology readiness level of 4-6 by 2025 [1]. Hence TeDP power systems research must be focused on the key challenges to meet these technology targets.

The HWB N3-X concept aircraft has been proposed [1] as a possible solution to meet the $\mathrm{N}+3$ performance, emission and noise targets. The thrust for the proposed N3-X aircraft will be provided by a TeDP system, in which a number of propulsor motors are powered by four generators, which are driven by two gas turbine engines [3]. Developing an electrical power system which is sufficiently light and efficient for a TeDP aircraft is a significant challenge.

High temperature superconducting (HTS) electrical machines have been proposed for TeDP systems due to their high power density compared to conventional electrical systems [4]. It is proposed that the majority of the system will be superconducting, operating at $77 \mathrm{~K}$, with the exception of the solid state switching components which will operate at $100 \mathrm{~K}[5]$.

The complexity of the proposed N3-X electrical power system architecture (Fig. 1 [5, 6]) creates a number of challenging problems in the development of a TeDP system which has a competitive efficiency and weight. These challenges can be classified according to three inter-dependent areas of TeDP systems research as outlined in Fig. 2: architectures, reliability and redundancy, and protection systems. These three areas also have a collective impact on system weight and efficiency, impacting on aircraft fuel burn and emissions.

This paper will discuss the motivation to develop an integrated system weight and efficiency sensitivity tool by identifying the key research questions and challenges which must be answered to develop a sufficiently light and efficient TeDP system. In addition, a modular and reconfigurable integrated system sensitivity tool will be presented. The potential of this tool to assist in the rapid appraisal of different TeDP architectures, protection systems and redundancy will be discussed.

\section{MOTIVATION FOR AN INTEGRATED SYSTEMS SENSITIVITY MODEL}

\section{A. Challenges of a complex, hybrid AC-DC network}

There are a number of advantages to implementing a hybrid AC-DC TeDP architecture, such as that shown in Fig. 1. Alongside taking advantage of the negligible resistive losses on a DC super-conducting network, it allows for the decoupling of the speed and torque of the generators and propulsor motors, enabling independent control of each, thus providing a degree of control flexibility [2]. In particular, by running the generators at higher speeds than the propulsor motors, the low pressure shaft of the engines can also be operated at higher speeds, enabling the utilization of more power dense and efficient engines $[1,3]$.

Solid state power electronic converters are the most suitable known technology to convert power from AC to DC 
and vice versa. These not only add significant weight to a system, but also incur significant losses [5]. Therefore, there is a challenge to not only minimize the number of converters within a TeDP system, but also to find new solid state switching technologies, materials and topologies which will reduce the weight and losses attributable to the converters. Numbers of converters may be optimized by architecture choice.

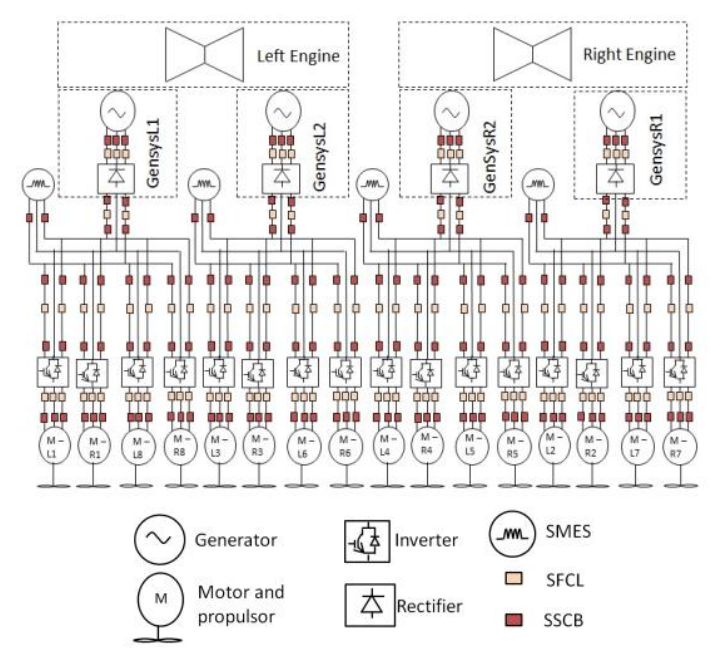

Fig. 1: Example electrical architecture of a 16 propulsor TeDP system.

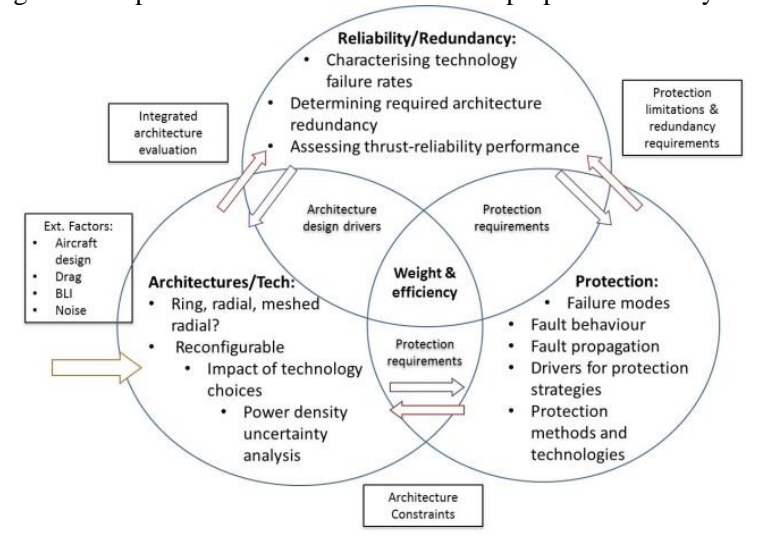

Fig. 2: TeDP systems focused research challenges

Potential architecture alternatives include radial, meshed radial or ring configurations. A ring architecture may allow for the reduction in the number of solid state converters. The inherent increase in the number of parallel supply paths to the motor loads [7] may result in increased security of supply, and hence impact on the system redundancy requirements. System redundancy requirements would also be impacted by developing a reconfigurable architecture [8].

Whilst it is outside the scope of this paper to discuss in detail, it may be possible to consider a fully AC architecture. The key advantage of such an architecture is that it significantly reduces the amount of solid state switching components within a TeDP architecture, hence reducing the weight and losses penalty associated with these components. However, either a gear box must be included, to enable the input shaft speed to the generators to be stepped down, or the $\mathrm{AC}$ frequency will need to be much higher, resulting in higher $\mathrm{AC}$ losses [11]. A disadvantage of such a system is that it has significantly less controllability than the hybrid AC-DC-AC system as the generators and motors are not decoupled via a DC-link. Further studies (beyond the scope of this paper) are required to fully investigate the trades and the advantages and disadvantages of the AC only system versus the hybrid ACDC architecture.

Alternatively, an AC-AC motor drive could be used with each propulsor motor [10]. This would provide decoupling between the generator and the motors, with lower rated power converters required. However, the power converters would still attract a weight and efficiency, penalty. Detailed trade studies are required to assess the potential weight and efficiency benefits of these other architectures.

Another approach to reducing overall system weight and losses may be to investigate using the converters to provide additional functionality. By implementing and utilizing a fault current blocking capability, the converters could form part of the system protection, reducing the number of additional protection components required and hence the total weight and losses incurred [5]. Protection strategies in superconducting DC systems are an ongoing area of research [9].

\section{B. Maximising system efficiency}

The superconducting power system has higher electrical power density, and is expected to have higher component reliability than a conventional electrical system due to the cold operating temperature [4]. However a cryogenic cooling system is required to maintain the low operating temperatures for the TeDP system, which negatively impacts on the overall weight and propulsive efficiency of the aircraft.

It is considered an achievable assumption that a cryocooler can be produced which will have a $30 \%$ Carnot Efficiency Brayton cycle $\left(\eta_{\text {carnot }}\right.$ in (1)), and a power density of $3 \mathrm{~kg} / \mathrm{kW}$ ( $k$ in (2)) [4]. Whilst the power density has been kept constant at $3 \mathrm{~kg} / \mathrm{kW}$, it should be noted that in reality it will decrease as power levels increase. The power and weight requirements of the cryocooler to maintain a particular operating temperature can be calculated using Equations 1 and 2. The electrical efficiency of the power system will impact directly on both the weight and electrical power requirements of the cryocooler, thus ultimately impacting on the overall electrical system efficiency $\left(\eta_{f u l l}\right.$, calculated using (3)).

$$
\begin{gathered}
P_{\text {cryo }}=\dot{Q} \frac{\left(T_{\text {amb }}-T_{\text {cool }}\right)}{T_{\text {cool }}} \eta_{\text {carnot }} \\
\text { weight }=k * P_{\text {cryo }} \\
\eta_{\text {full }}=\frac{P_{\text {gen }}-\left(P_{\text {total cryo }}+P_{\text {total elec losses }}\right)}{P_{\text {gen }}}
\end{gathered}
$$


In this expression $\dot{Q}$ is heating to the coolant and temperatures

$T_{a m b}$ and $T_{c o o l}$ represent ambient and cryocoolant conditions. 
Most of the electrical power losses within the TeDP system will be dissipated as heat. Therefore, there is a need to minimize electrical losses throughout the whole TeDP system, by identify components and sections of subsystems which are dominating the electrical losses. This will allow future research to focus on different architectures, protection strategies and technologies which can reduce these losses to an acceptable level.

The optimum number of generators and propulsor motors must be selected to ensure that the minimum required propulsive power is provided at all times. For example, the ratings of the motors in the 16 propulsor motor architecture shown in Fig. 1, are such that 2 propulsor motors can be disabled, and full thrust can still be achieved [5]. This overrating will attract a significant weight and efficiency penalty. However the level of redundancy required in a system will be driven not only by component reliability, but by choices of architecture and protection system. Future certification requirements are also likely to influence the required level of redundancy [9].

\section{INTEGRATED SYSTEM SENSITIVITY TOOL DESCRIPTION}

\section{A. The role of the tool}

To highlight the key research questions which must be tackled to meet the ambitious $\mathrm{N}+3$ performance targets, an integrated TeDP system pre-design sensitivity tool has been developed. This tool enables the rapid appraisal of different TeDP electrical power systems designs, where the impact of architectural features, protection strategies and redundancy measures can be quickly evaluated and compared.

\section{B. Tool specification}

This parametric analysis tool enables the sensitivity of the weight and efficiency of a particular TeDP architecture to system parameters and optimum operating regions identified. Example system parameters may include voltage, fault current ratio or system power level. To achieve this and enable quick comparisons between different system configurations, the tool is designed to be easily reconfigurable.

In addition, the modular nature of the tool allows for the impact of individual components on weight and efficiency to be analyzed; highlighting areas of a particular TeDP system which have significant impact on system weight and efficiency.

\section{Electrical component sensitivity models}

\section{1) Generic, hierarchical structure}

The reconfigurable integrated system has been achieved by developing a sensitivity model of the electrical components which make up a TeDP system: electrical machines, power electronic converters, cables, energy storage, solid state circuit breakers (SSCBs) and superconducting fault current limiters (SFCLs).
Each component model has a generic, hierarchical structure, with two types of input variables at the top level: control variables and sensitivity variables. Table 1 details the control and sensitivity variables for the different components.

There is a discrete set of sensitivity data for each combination of control variables for a particular component. The sensitivity data was obtained from models described in [5, 6], and is stored in multi-dimensional look-up tables. Linear interpolation has been used between data points. So for example, for a power converter, there are three separate sets of data, one for each power level (control variable). The data is held in 3-D look up tables. The axes of the look-up tables are $\mathrm{DC}$ voltage, fault current ratio and $\mathrm{AC}$ frequency.

\section{2) Cryocooler}

To maintain sufficient redundancy, a separate cryocooler is proposed for each set of components [5]. The weight and power for each cryocooler is modelled using Equations 1 and 2.

\section{3) Integrated TeDP system sensitivity model}

By inspection of Fig. 1 it can be seen that the full TeDP architecture consists of 4 identical radial power system sections, one of which is shown in Fig. 3. The library of component models developed has been used to build a systems level sensitivity model for the section of TeDP network shown in Fig. 3.

As indicted in Table 1, certain components, such as the cables, are sensitive to power levels. Therefore, the net power input, to each of these sections is calculated, including electrical and cryocooler power losses. The net power to each of the motors is also calculated. It is assumed that all the propulsor fans are operating at the same speed and the voltage drops along cables and across other equipment are also neglected.

TABLE 1: SENSITIVITY AND CONTROL VARIABLES

\begin{tabular}{|c|c|c|}
\hline Component & $\begin{array}{c}\text { Sensitivity } \\
\text { variables }\end{array}$ & Control variables \\
\hline $\begin{array}{l}\text { Electrical } \\
\text { Machines }\end{array}$ & $\begin{array}{c}\text { Electrical Speed, } \\
\text { Peak Electrical } \\
\text { Power }\end{array}$ & - \\
\hline $\begin{array}{l}\text { Power Electronic } \\
\text { Converters (AC- } \\
\text { DC, DC-AC) }\end{array}$ & $\begin{array}{l}\text { Voltage, Fault } \\
\text { Current Ratio, } \\
\text { AC Frequency }\end{array}$ & Power Rating \\
\hline Cables (AC, DC) & $\begin{array}{c}\text { Power, AC } \\
\text { Frequency, } \\
\text { Length, Voltage }\end{array}$ & $\mathrm{AC}$ or $\mathrm{DC}$ \\
\hline $\begin{array}{c}\text { Energy Storage } \\
\text { Unit (SMES with } \\
\text { DC-DC } \\
\text { converter) }\end{array}$ & $\begin{array}{l}\text { Voltage, } \\
\text { Magnetic Field, } \\
\text { Compressive } \\
\text { Quality Factor }\end{array}$ & $\begin{array}{l}\text { Energy Capacity } \\
\text { Type of Coolant } \\
\text { Aspect Ratio }\end{array}$ \\
\hline SFCL & $\begin{array}{l}\text { Voltage, Fault } \\
\text { Current Ratio, } \\
\text { Time to Isolation }\end{array}$ & $\begin{array}{c}\text { Power Rating } \\
\text { Desired Resistance } \\
\text { Desired Inductance } \\
\text { Time for Heat Dissipation }\end{array}$ \\
\hline SSCB & $\begin{array}{l}\text { Voltage, Fault } \\
\text { Current Ratio }\end{array}$ & Power Rating \\
\hline
\end{tabular}




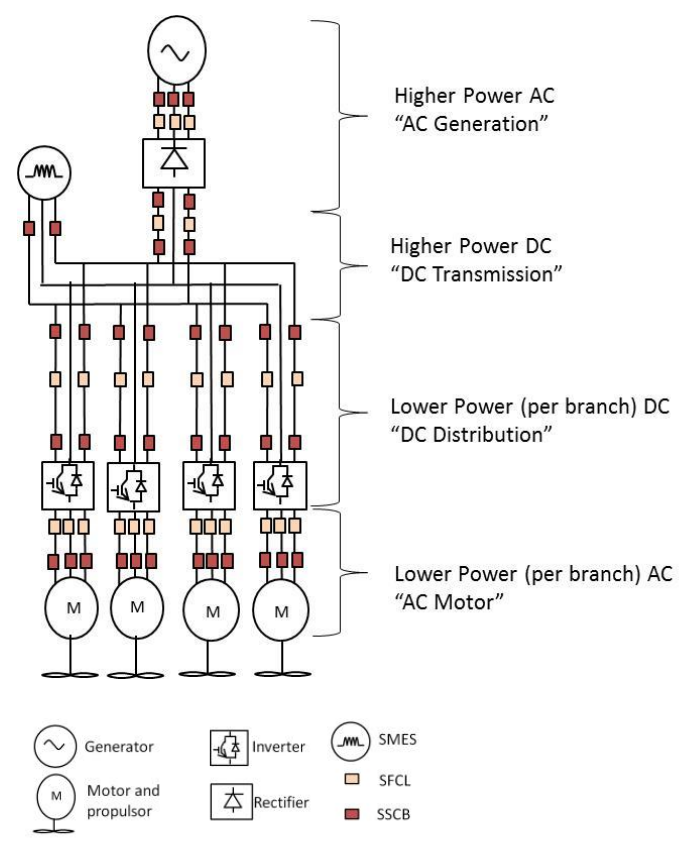

Fig. 3: Subsystem of a full TeDP network.

\section{IDENTIFICATION OF INFLUENTIAL COMPONENTS AND SUB- SYSTEMS}

\section{A. Impact of electrical losses on system performance}

As identified earlier, system protection, architecture and redundancy all have an impact on overall system weight and efficiency. As outlined in Table 1, most of the TeDP components are sensitive to voltage. Therefore, a voltage sensitivity study was run using the developed integrated system architecture for the model shown in Fig. 3.

In this system, the converters were set to have a switching frequency of $5 \mathrm{kHz}$. The high power converter and generator were rated at $12.5 \mathrm{MW}$, and the lower power inverters were rated at $2.5 \mathrm{MW}$ each. Figs $4 \mathrm{a}-\mathrm{c}$ show the sensitivity of the system weight, losses and efficiency to the DC distribution voltage level.

From Figs 4a-c, it is clear that the weight of the cryocooling system is driven by electrical losses and that the contribution of the cryocooling system to the total system weight is significant. Hence it is apparent that a reduction in electrical losses will have more impact on overall aircraft weight and fuel efficiency than a reduction in electrical system weight.

Due to the modular nature of the model, the sensitivity analysis of the fully integrated system can be analyzed on a component by component basis. Figs 5a and 5b illustrate the components or subsystems which dominate the electrical system losses. From these results, the solid state switching components can be identified as dominating the weight and efficiency of the system. Fig. 5c indicates that the electrical machines and SMES (which contains a DC-DC converter) are the next most influential components. Hence if the influence of the switching components were significantly reduced, due to improved efficiency or different architectures, then the electrical machines and SMES would have greater influence on system performance. The cables and SFCLs have little impact on system weight and efficiency.

Therefore to improve system performance, and maintain the significant benefits provided by using a hybrid AC-DC$\mathrm{AC}$ architecture, compared to a purely AC system, then the development of more power dense and efficient power electronics for superconducting power systems needs to be at the focus of future research.

To lower the impact of the solid state switching devices on the overall system weight and efficiency, reducing the electrical weight will only have a limited impact. If however the solid state switching electrical losses ("switching losses") can be reduced, this will impact on both the power and weight requirements of the cryocooler system.

Figs. $6 \mathrm{a}$ and $6 \mathrm{~b}$ show the results from running a suite of studies where the sensitivity of the system weight and losses to DC voltage was investigated as the switching losses were steadily reduced from the baseline case (system losses set as for studies in Figs 4 and 5) and then reduced to 80\%, 60\%, $40 \%$ and $20 \%$ of the baseline losses.

\section{B. Discussion of results}

Figs $6 \mathrm{a}$ and $6 \mathrm{~b}$ demonstrate how variation in the switching losses reduces the system sensitivity to voltage, particularly in terms of efficiency. This is due to the increased influence of the electrical machines, which were considered largely insensitive to voltage levels. The reduction in sensitivity to certain parameters would enable greater flexibility in power system architecture, protection and redundancy choices.

As the electrical losses associated with the solid state switching components are reduced, the overall system weight decreases, as cryocooler requirements decrease. However the electrical weight of the solid state switching components remains unchanged. Hence whilst the influence of other components (electrical machines in particular) increases as the switching losses are decreased, the system weight continues to be dominated by the solid state switching components. Therefore the impact of the other components on system weight is not as great as it is for system efficiency as the solid state switching losses decrease.

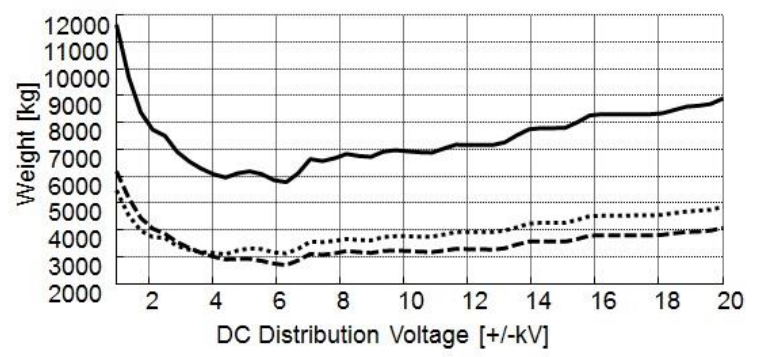


- Total for system

- Cryocooler contribution

...... Electrical system contribution

Fig. 4a: Sensitivity of system weight with voltage.

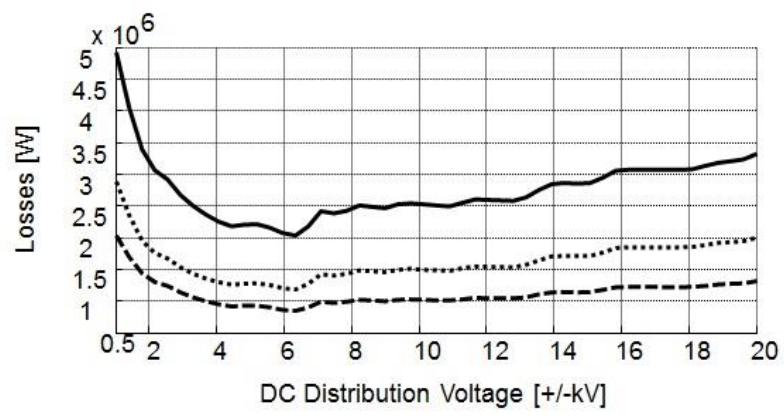

- Total for system

- - Cryocooler contribution

...... Electrical system contribution

Fig. 4b: Sensitivity of system losses with voltage.

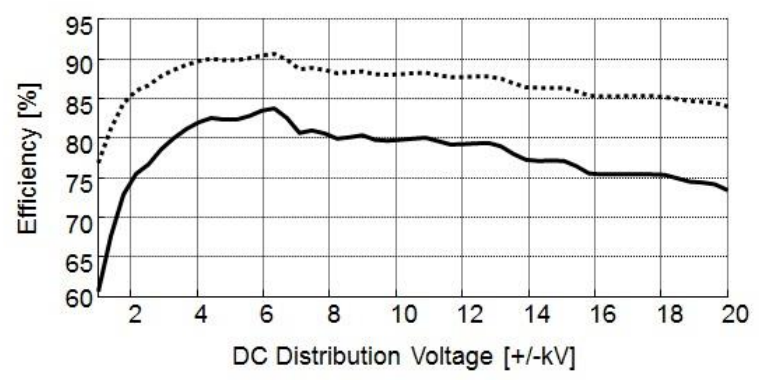

- Total system efficiency

Electrical system efficiency

Fig. 4c: Sensitivity of efficiency with voltage
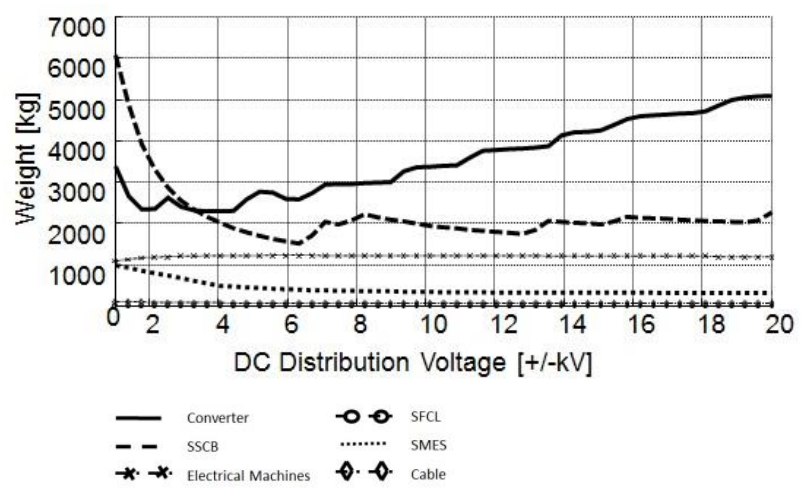

Fig. 5a: Sensitivity of the weight of different components to voltage.

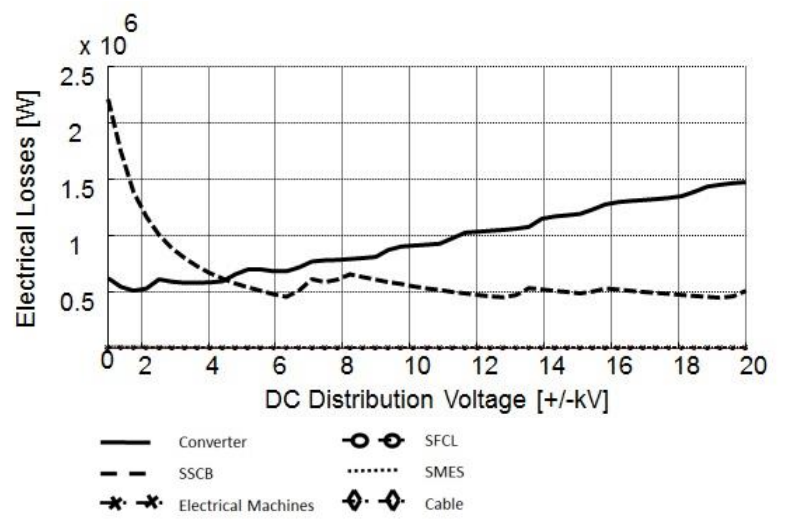

Fig. 5b: Variation of the electrical losses of different components with voltage.

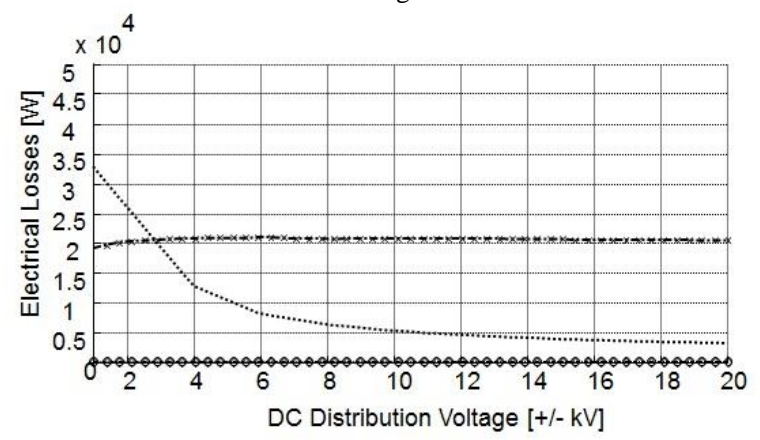

Fig. 5c: Same results as presented in Fig 5b, but focusing on components with electrical losses under $50 \mathrm{~kW}$.

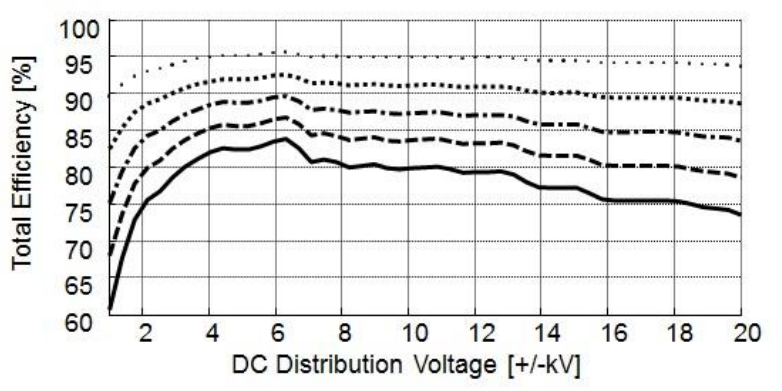

$$
\begin{array}{llll} 
& \text { Baseline case } & \ldots . . . & 40 \% \text { baseline case } \\
\text { - } & 80 \% \text { baseline case } & \ldots . & 20 \% \text { baseline case } \\
\text { - . . } & 60 \% \text { baseline case } & &
\end{array}
$$

Fig. 6a: Sensitivity of system efficiency to voltage as switching losses vary.

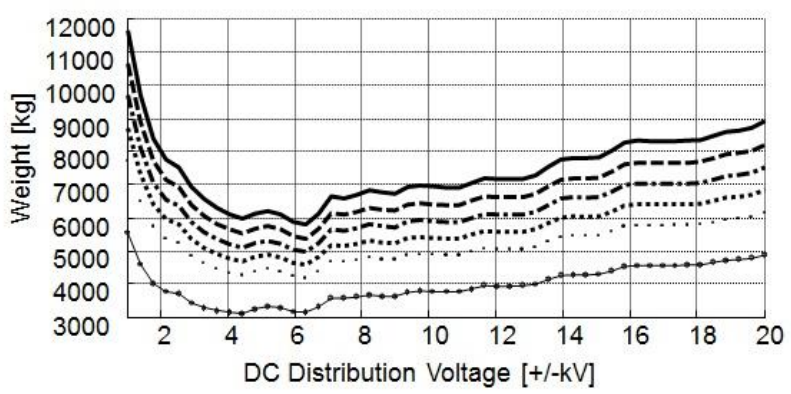


- Baseline case $\quad$......... $40 \%$ baseline case

- - $80 \%$ baseline case $\quad \ldots \quad 20 \%$ baseline case

- $60 \%$ baseline case Electrical system weight

Fig. 6b: Sensitivity of system weight to voltage as switching losses vary.

Due to the aerospace application of this power system, the impact of these variations on fuel burn is of particular interest. According to [4], increase in fuel burn due to added weight can be estimated by assuming a fractional change in average aircraft weight (in this case due to changes in electrical system mass) proportional to a fractional change in fuel burn. Table 2 provides estimates of the decrease in fuel burn as a consequence of a lower electrical power system weight (including the cryocooling system) due to reducing the switching losses.

An estimated weight of the $\mathrm{N} 3-\mathrm{X}$ aircraft without the electrical power system has been estimated in the literature to be $211,110 \mathrm{~kg}$ [4]. The full electrical power system weight is the weight in Fig.6c multiplied by 4 to represent the weight of the full TeDP system shown in Fig.1. The results indicate a drop of circa $0.6 \%$ in fuel burn per $20 \%$ drop in switching losses. However, this calculation is heavily dependent on the estimated weight of the full aircraft. If the weight of the full aircraft, without the electrical system, is reduced by $1 / 5$, then as indicated in Table 2, there is circa $0.8 \%$ less fuel burn per $20 \%$ drop in losses. These results may be somewhat conservative: the impact of a lower structural mass on fuel burn due to a lower electrical mass has not been included at this stage.

In addition, future aircraft level mission analysis and design iteration is required to estimate how much a $12 \%$ increase in electrical power system efficiency (due to an $80 \%$ reduction in switching losses) would have on fuel burn.

\section{CONCLUSIONS}

This paper discusses an integrated TeDP electrical systems sensitivity tool developed by the authors. From the initial sensitivity study findings presented, a number of observations can be made:

- The development of a competitive super-conducting aeroelectrical system for a TeDP concept aircraft requires a significant reduction of the electrical losses in the system.

- Solid state switching components have been identified as having the most influence over system weight and efficiency.

- Reducing the impact of one element on the system may significantly change other system sensitivities (e.g. shift of optimal operating voltage due to efficiency improvement).

The authors will continue to use the sensitivity analysis tool presented in this paper to further explore optimal architectures, protection strategies and redundancy measures for full and hybrid concept aircraft, supporting the identification and development of game-changing technologies.

\section{Acknowledgment}

This work has been carried out as part of the Rolls-Royce UTC programme.

\section{References}

1] J.L. Felder, G.V. Brown, H.D. Kim and J. Chu, "Turboelectric Distributed Propulsion in a Hybrid Wing Body Aircraft", International Society for Air Breathing Engines Conference, ISABE-2011-1340, 2011

[2] C. A. Luongo et al, "Next Generation More-Electric Aircraft: A Potential Application for HTS Superconductors", IEEE Transactions on Applied Superconductivity, Vol. 19, No. 3, 2009, pp. 1055-1068.

[3] J.L. Felder, H.D.Kim, G.V. Brown and J. Chu, "An Examination of the Effect of Boundary Layer Ingestion on Turboelectric Distributed Propulsion Systems", 49 ${ }^{\text {th }}$ AIAA Aerospace Sciences Meeting, AIAA2011-300, 2011

TABLE 2: ESTIMATION OF CHANGE IN FUEL BURN DUE TO

\begin{tabular}{|l|l|l|l|l|l|}
\hline Case & $\begin{array}{l}\text { Minimum } \\
\text { Electrical } \\
\text { system } \\
\text { weight } \\
{[\mathrm{kg}]}\end{array}$ & \multicolumn{2}{|l|}{$\begin{array}{l}\text { Net aircraft weight } \\
\text { without electrical } \\
\text { power system } \\
211,110 \mathrm{~kg}\end{array}$} & \multicolumn{2}{|l|}{$\begin{array}{l}\text { Net aircraft weight } \\
\text { without electrical } \\
\text { power } \\
\text { system }\end{array}$} \\
\cline { 3 - 6 } & $\begin{array}{l}\text { Increase } \\
\text { in } \\
\text { weight } \\
\text { from } \\
\text { electrical } \\
\text { power } \\
\text { system }\end{array}$ & $\begin{array}{l}\text { Change } \\
\text { in fuel } \\
\text { burn } \\
\text { from } \\
\text { baseline }\end{array}$ & $\begin{array}{l}\text { \% } \\
\text { aircraft } \\
\text { weight } \\
\text { due to } \\
\text { electrical } \\
\text { power } \\
\text { system }\end{array}$ & $\begin{array}{l}\text { lom } \\
\text { change } \\
\text { in fuel } \\
\text { burn } \\
\text { from } \\
\text { baseline }\end{array}$ \\
\hline Baseline & 23200 & $9.9 \%$ & n/a & $12 \%$ & n/a \\
\hline $\begin{array}{l}80 \% \\
\text { baseline } \\
\text { losses }\end{array}$ & 21600 & $9.2 \%$ & $-0.7 \%$ & $11.3 \%$ & $-0.7 \%$ \\
\hline $\begin{array}{l}60 \% \\
\text { baseline } \\
\text { losses }\end{array}$ & 20000 & $8.6 \%$ & $-1.3 \%$ & $10.5 \%$ & $-1.5 \%$ \\
\hline $\begin{array}{l}40 \% \\
\text { baseline } \\
\text { losses }\end{array}$ & 18400 & $8.0 \%$ & $-1.9 \%$ & $9.8 \%$ & $-2.2 \%$ \\
\hline $\begin{array}{l}20 \% \\
\text { baseline } \\
\text { losses }\end{array}$ & 16800 & $7.3 \%$ & $-2.6 \%$ & $9.0 \%$ & $-3 \%$ \\
\hline & & & & & \\
\hline
\end{tabular}

CHANGES IN ELECTRICAL SYSTEM WEIGHT

[4] G.V. Brown, "Weights and Efficiencies of Electric Components of a Turboelectric Aircraft Propulsion System", 49 ${ }^{\text {th }}$ AIAA Aerospace Sciences Meeting, AIAA-2011-225, 2011.

[5] M. Armstrong, M. Blackwelder and C. Ross, "Sensitivity of TeDP Microgrid Systems Weight and Efficiency to Operating Voltage", 50 AIAA/SAE/ASEE Joint Propulsion Conference, 2014. 
[6] C. Ross, M. Armstrong, M. Blackwelder, C. Jones, S. Fletcher and P. Norman, "Turboelectric Distributed Propulsion Protection System Design Trades", SAE Aerospace Systems and Technology Conference, 2014-01-2141, 2014.

[7] S. Fletcher, P. Norman, P. Rakhra, S. Galloway and G. Burt, "Modeling and Simulation Enabled UAV Electrical Power System Design", SAE Aerospace Systems and Technology Conference, 2011-01-2645, 2011.

[8] J. Shaw, P. Norman, S. Galloway and G. Burt, "A Method for the Evaluation of the Effectiveness of Turboelectric Distributed Propulsion Power System Architectures", SAE Int. Journal of Aerospace, 7(1), 2014, pp. 35-43.

[9] K. Davies, P. Norman, C. Jones, S. Galloway and G. Burt, "Modelling the Fault Behaviour of a Superconducting Turboelectric Distributed Propulsion Network", SAE Aerospace Systems and Technology Conference, 2014-09-16, 2014.

[10] H.D. Kim, G.V. Brown and J.L. Felder, "Distributed Turboelectric Propulsion for Hybrid Wing Body Aircraft", Royal Aeronautical Society International Powered Lift Conference, 2008.

[11] P. Miller, "Potential Propulsion Solutions for Hybrid-Electric Aircraft" (presentation), IMechE Disruptive Green Propulsion Technologies Conference, November 2014. 